\title{
BMJNeurology Open Variations in the patterns of prevalence and therapy in Australasian Parkinson's disease patients of different ethnicities
}

\author{
Yassar Alamri (D) , 1,2 Toni Pitcher, ${ }^{3}$ Tim J Anderson ${ }^{3,4}$
}

To cite: Alamri Y, Pitcher T, Anderson TJ. Variations in the patterns of prevalence and therapy in Australasian Parkinson's disease patients of different ethnicities. BMJ Neurology Open 2020;2:e000033. doi:10.1136/ bmjno-2019-000033

Received 19 December 2019 Revised 24 February 2020 Accepted 02 March 2020
Check for updates

(c) Author(s) (or their employer(s)) 2020. Re-use permitted under CC BY-NC. No commercial re-use. See rights and permissions. Published by BMJ.

${ }^{1}$ Department of General Medicine, Canterbury District Health Board, Christchurch, New Zealand

${ }^{2}$ Department of Medicine, University of Otago Christchurch, Christchurch, New Zealand ${ }^{3}$ New Zealand Brain Research Institute, Christchurch, New Zealand

${ }^{4}$ Department of Neurology, Canterbury District Health Board, Christchurch, New Zealand

Correspondence to Dr Yassar Alamri; yassar.alamri@nzbri.org

\begin{abstract}
Parkinson's disease (PD) is the second most common neurodegenerative disease in the elderly after Alzheimer's disease. It is expected that PD cumulative incidence will increase in the future, as there are far more people surviving into late age than there ever used to be. While most commonly idiopathic, rare forms of PD can be familial/ genetic. In addition, socioeconomic, cultural and genetic factors may influence the way in which anti-parkinsonian medications are prescribed, and how patients respond to them. This review aims to highlight the potential impact of genetic variation on the epidemiology and therapeutics of PD, focusing on data from New Zealand and Australia.
\end{abstract}

\section{INTRODUCTION}

Parkinson's disease (PD) is a degenerative disorder that primarily affects the nervous system. While the pathophysiology underlying idiopathic PD has long been elusive to pinpoint, mounting evidence is implicating neuroinflammation as a central, although not exclusive, precipitating and perpetuating culprit. ${ }^{1}$ PD is the second most common neurodegenerative disease in the elderly after Alzheimer's disease. ${ }^{2}$ Since PD is an age-related disorder, it is expected that PD cumulative incidence will increase in the future, as there are far more people surviving into late age than there ever used to be. The increase may not be continuous, however, as PD incidence appears to decline in persons surviving past 85 years of age. ${ }^{3}$ The present review aims to highlight the impact of genetic variation on the epidemiology and therapeutics of PD, focusing on data from New Zealand and Australia.

\section{ETHNIC VARIATION IN PD EPIDEMIOLOGY General remarks}

PD is often quoted to have a global prevalence rate of $0.3 \%$, although this figure increases substantially when populations are age-stratified. ${ }^{4}$ For example, the prevalence of PD may reach 1.9\% (1903 per 100 000) of persons 80 years and older, while persons under 40 years of age represent only $5 \%$ to
$10 \%$ of all PD patients. ${ }^{4}$ Among all neurological disorders, PD is the only one to have exhibited increased age-standardised prevalence between 1990 and $2015 .^{4}$

As evident from the literature, prevalence rates can vary considerably according to, for example, the diagnostic criteria used in a particular study or the methodology of screening. ${ }^{5}$ In addition, it is likely due to ethnic and sociodemographic differences and time since publication, reported prevalence rates of PD vary widely in the published literature. ${ }^{6}$

\section{PD in Māori and New Zealand Europeans}

Recent studies have shed some light on the prevalence and incidence of PD in New Zealand. ${ }^{3} 7$ Using national health data sets, the total adult population of the country was studied, with case identification through the use of anti-parkinsonian medications, and diagnostic information gained from both national and local databases. The 2013 age-standardised and sex-standardised incidence was estimated to be 31 per 100000 person-years, and the age-standardised and sex-standardised prevalence to be 210 per 100000 people. $^{3}$

Given that New Zealand is a multicultural society, PD within the major ethnic groups represented in the population (New Zealand European, Māori, Pasifika (Polynesian) and Asian) was also assessed. ${ }^{7}$ Māori-the indigenous people of New Zealand-had substantially lower age-standardised and sexstandardised incidence and prevalence rates compared with New Zealand Europeans. The incidence of PD in Māori was 20 per 100000 per year (compared with 33 in New Zealand Europeans), and PD prevalence was 114 per 100000 in Māori (compared with 223 in New Zealand Europeans). ${ }^{7}$

The underlying causes of such a lowincidence in Māori are unknown, but a number of factors may be contributing. Such potential factors include inequitable access to healthcare, differential treatment within the healthcare system 
once it is accessed, differing rates of both potentially protective and risk-increasing lifestyle and co-morbidity factors and possible genetic differences among ethnic groups. Furthermore, one ought to be cognisant of potential methodological flaws in studies reporting PD incidence in Māori based on surrogate markers. For example, a study that estimates PD prevalence among Māori from drug prescription data may overlook Māori patients with PD who do not take medications or never fill their prescriptions.

Māori are known to face a number of health disparities in terms of access to and treatment within the healthcare system. ${ }^{8}$ There are no data specific to neurological disorders, but there is no reason to suspect that healthcare services encountered by people with PD, or neurological disorders in general, are achieving greater engagement with Māori compared with services for other conditions.

Māori are known to have comparatively high rates of smoking ${ }^{9}$ and hyperuricaemia, ${ }^{10}$ both of which have often been shown to be associated with lower rates of PD. ${ }^{11} 12$ Māori are also known to have high rates of hypertension. ${ }^{13}$ Hypertension can be treated with calcium channel blockers, which have the potential to protect against the development of $\mathrm{PD},{ }^{14}$ although a recent phase III clinical trial did not show isradipine (a calcium-channel blocker) to slow the progression of the disease. ${ }^{15}$

Māori also have high rates of type 2 diabetes which has been associated with an increased risk of PD in prospective population studies, ${ }^{16}$ but not case-control studies. ${ }^{17}$ Glitazones $^{18}$ and dipeptidyl peptidase- 4 inhibitors ${ }^{19}$ used as a treatment of type 2 diabetes have been associated with reduced risk of PD. Another treatment for type 2 diabetes, metformin, may also be offering some protection from PD. Animal studies have indicated that metformin is capable of preventing dopamine neuron death in rodent models of the disease, ${ }^{20} 21$ although population level have had mixed results. ${ }^{1622}$ Although these same factors (ie, hyperuricaemia, hypertension and type 2 diabetes) also hold true for the Pasifika group, Māori were found to have lower incidence and prevalence compared with Pasifika. ${ }^{7}$

No data are available on the expression of potential PD genetic risk factors within the Māori population, but it is possible that differential expression of risk alleles across ethnic groups could be present, as this has been shown for alleles associated with multiple sclerosis. ${ }^{23}$ As a population, Māori also have a substantially lower incidence of multiple sclerosis and motor neuron disease compared with New Zealand Europeans. ${ }^{24}$

\section{PD in other ethnic groups in New Zealand}

The incidence and prevalence of PD in the Asian and Pasifika groups in New Zealand were intermediate between rates in Māori and New Zealand Europeans (Asian: incidence 28, prevalence 174; Pasifika: incidence 27 , prevalence 160). ${ }^{7}$ The lower incidence and prevalence in the Asian group compared with the New Zealand Europeans follow international literature, where Asian populations have generally been shown to develop PD at rates lower than populations of Caucasian/European descent. ${ }^{2526}$ Although often these comparisons have been made across studies conducted in different countries, and using different methodology, a similar pattern has been evident when comparing ethnic groups within the American population. ${ }^{427}$

\section{PD in Australia}

The most recent nationwide estimate of PD in Australia is from a Deloitte report on the economic cost of the disease. ${ }^{28}$ This report used prescription data and estimated a prevalence of 294 per 100000 population as at 2014. The report did not, however, consider individual ethnic groups represented within the Australian population.

There is growing recognition that more detailed Australian-specific data are required and that special consideration should be given to obtaining estimates for the indigenous Aboriginal and Torres Strait Islander populations of Australia. ${ }^{29}$ The best indication of PD in those indigenous groups comes from a burden-of-diseaseand-injury report, specifically targeted at these populations, in the state of Queensland. ${ }^{30}$ This report indicated that PD is ranked as the 10th leading cause of non-fatal burden of disease or injury for indigenous groups aged 60-74 years (contributing to $2.3 \%$ of total burden) and $\geq 75$ years (contributing to $3.1 \%$ ). This is compared with PD being the 6th leading cause of non-fatal burden in the non-indigenous population for the group aged 60-74 years (contributing to $4 \%$ ), and the 10 th leading cause in the group aged $\geq 75$ years (contributing to $3.7 \%$ ). ${ }^{30}$ Although burden of disease and prevalence are not synonymous, one might infer from this report that Australian indigenous populations also experience PD at lower rates than the non-indigenous population.

\section{PD outside Australasia}

In the 2015 GBD study on burden of neurological disorders, ${ }^{31}$ the prevalence of PD was found to be the lowest in sub-Saharan Africa and Eastern Europe. Similarly, lower prevalence of PD has been reported among Asian and Latin American populations. ${ }^{31}$ Although the limited life expectancy may have played a factor, it is unlikely to fully explain the discrepant prevalence. In a recent review of PD prevalence among Arabs, ${ }^{32}$ the reported rates were found to vary widely (from 27 to 557.4 cases per 100000 people). Arab families generally tend to be large units with a high rate of consanguineous marriages, thereby increasing the risk of genetic and familial disorders, including genetic forms of PD. ${ }^{32}$

\section{ETHNIC VARIATION IN PD THERAPY}

Use of anti-parkinsonian medications among various ethnic groups

Accurate assessment of racial and ethnic differences in PD management is hampered by a multitude of factors. These may be grouped into prediagnosis factors (eg, differences in PD prevalence), postdiagnosis factors (eg, choice of medication and lower access to specialist neurologists) and treatment-related factors (eg, ethnicity-specific 
response to medications and lower recruitment into clinical trials).

Factors that may influence racial differences in treatment prior to PD diagnosis include the observed variation in disease incidence and prevalence among the various ethnic groups. For example, the use of anti-parkinsonian medications has been found to be lower in PD patients of African-American descent compared with white Americans. The authors attributed such discrepancy to the possible lower prevalence of PD in African Americans. ${ }^{33}$

Once a diagnosis of $\mathrm{PD}$ is established, other factors may come into play which contribute to ethnic variations in PD therapy. Racial disparities in healthcare access (including access to specialist neurologists) may influence the type of treatment, patient adherence to management plans, as well as referrals for more advanced treatment options (eg, deep brain stimulation). ${ }^{34}$ How cultural beliefs vis-à-vis advanced and potentially invasive PD therapies among indigenous populations influence access to such treatments is yet to be determined.

Moreover, the choice and dosing of anti-parkinsonian medications were shown to vary by the patient's ethnicity. Within the analyses by Myall $e t a l^{3}$ and Pitcher $e t a l^{7}$ it was noted that many of the Māori cases, identified by receiving anti-parkinsonian medications, were ultimately classified as having a low probability of PD. This was due to anticholinergics being the sole anti-parkinsonian medication prescribed to these people. For most of these people, only mental health diagnoses, rather than neurological ones, were identified. ${ }^{7}$

Māori who were assigned a high probability of PD tended to start on higher-than-usual doses of medication (unpublished observations). Whether this reflects a more rapid progression of the disease in Māori or that they are diagnosed later in the disease process (potentially related to access to, and treatment within, the healthcare system) remains unclear.

Finally, treatment-related factors may exacerbate observed differences in treatment among PD patients of different ethnicities. Lower health literacy in disadvantaged racial groups often translates to suboptimal management of chronic conditions, including PD. ${ }^{34}$ Furthermore, fewer patients from these disadvantaged racial groups tend to be recruited into clinical trials. ${ }^{34}$

\section{Expert opinion: does the efficacy of anti-parkinsonian medications vary among different ethnicities?}

There is no published information regarding efficacy of anti-parkinsonian therapies stratified by ethnicity in Australasia. Indeed, only scant such literature relating to ethnicity in other world regions exists. In a study of pramipexole treatment in PD, there was no significant difference in efficacy by race or ethnicity. ${ }^{35}$ Although one might expect such variations, not only in efficacy, but also in adverse effects-because of genetic (including epigenetic) or socioeconomic factors-very little is known about this. The concept of variations in drug responsiveness relating to ethnicity has been controversial. In 2001, a study published in the New England Journal of Medicine suggested that enalapril was more effective in white than black American patients, at least in preventing hospitalisation. ${ }^{36}$ The publication, in turn, led to some practitioners in the USA not to prescribe ACE inhibitors to black Americans. ${ }^{37}$

Response to medications may be affected by polymorphisms in genes influencing drug metabolism, and polymorphism frequency can vary among populations with different ancestries. Although this factor might suggest that differences in response to medications, including anti-parkinsonian drugs, could be ascribed to genetic differences among ethnic groups, there are many other explanations, including the influence of lifestyle, socioeconomic status and general health. ${ }^{38}$ There are no data to date that examine the prevalence and/or effect of genetic polymorphisms among Australasian indigenous populations in the magnitude of response to anti-parkinsonian medications (eg, Val158Met COMT polymorphism) or probability of developing side effects (eg, impulse-control disorders in response to dopamine replacement therapies).

It also needs to be recognised that with increasing diversity of populations in Australasia, allelic frequency will vary considerably within each ethnic group. While it is true that, overall, there may be some differences in genetic influences on anti-parkinsonian drug response among ethnic populations in both Australia and New Zealand, there will be much overlap, and such differences will almost certainly be very small. As genes that contribute to anti-parkinsonian drugs response are increasingly identified, clinicians will be better informed to take genotypeand certainly not ethnicity or racial group-into account when prescribing one medical class over another. ${ }^{39}$

\section{CONCLUSIONS}

The prevalence of PD is likely to increase with the ageing population, although affecting patients of various ethnicities differently. Accurate assessment of the response to PD medications among patients of different ethnic backgrounds is stifled by a range of factors, including the general lack of studies in the area. While some of the ethnic differences are unavoidable (eg, genetic predilections), other discrepancies ought to be addressed and rectified (eg, equitable access to timely diagnosis, treatment options and community supports). Finally, as finer clinical tools (eg, genetic markers and panels) are made available, personalised (cf. ethnic) medicine will be the way forward.

Contributors YA conceived the idea and co-wrote the manuscript; TP co-wrote the manuscript; TA conceived the idea and provided supervisory support for the study.

Funding The authors have not declared a specific grant for this research from any funding agency in the public, commercial or not-for-profit sectors.

Competing interests None declared.

Patient consent for publication Not required.

Provenance and peer review Commissioned; externally peer reviewed. 
Open access This is an open access article distributed in accordance with the Creative Commons Attribution Non Commercial (CC BY-NC 4.0) license, which permits others to distribute, remix, adapt, build upon this work non-commercially, and license their derivative works on different terms, provided the original work is properly cited, appropriate credit is given, any changes made indicated, and the use is non-commercial. See: http://creativecommons.org/licenses/by-nc/4.0/.

ORCID iD

Yassar Alamri http://orcid.org/0000-0003-2519-3593

\section{REFERENCES}

1 Barnum CJ, Tansey MG. Neuroinflammation and non-motor symptoms: the dark passenger of Parkinson's disease? Curr Neurol Neurosci Rep 2012;12:350-8.

2 Mehta P, Kifley A, Wang JJ, et al. Population prevalence and incidence of Parkinson's disease in an Australian community. Intern Med J 2007;37:812-4.

3 Myall DJ, Pitcher TL, Pearson JF, et al. Parkinson's in the oldest old: impact on estimates of future disease burden. Parkinsonism Relat Disord 2017;42:78-84.

4 Pringsheim T, Jette N, Frolkis A, et al. The prevalence of Parkinson's disease: a systematic review and meta-analysis. Mov Disord 2014;29:1583-90.

5 Tanner CM. PD or not PD? That is the question. Neurology 2003;61:5-6.

6 Caradoc-Davies TH, Weatherall M, Dixon GS, et al. Is the prevalence of Parkinson's disease in New Zealand really changing? Acta Neurol Scand 1992;86:40-4.

7 Pitcher TL, Myall DJ, Pearson JF, et al. Parkinson's disease across ethnicities: a nationwide study in New Zealand. Mov Disord 2018;33:1440-8.

8 Howden-Chapman P, Blakely T, Blaiklock AJ, et al. Closing the health gap. N Z Med J 2000;113:301-2.

9 Statistics New Zealand. Tobacco smoking, 2013. Available: http:// archive.stats.govt.nz/browse_for_stats/snapshots-of-nz/nz-socialindicators/Home/Health/tobacco-smoking.aspx [Accessed 06 Sep 2019].

10 Dalbeth N, House ME, Horne A, et al. The experience and impact of gout in Māori and Pacific people: a prospective observational study. Clin Rheumatol 2013;32:247-51.

11 Kiyohara C, Kusuhara S. Cigarette smoking and Parkinson's disease: a meta-analysis. Fukuoka Igaku Zasshi 2011;102:254-65.

12 Shen C, Guo Y, Luo W, et al. Serum urate and the risk of Parkinson's disease: results from a meta-analysis. Can J Neurol Sci 2013;40:73-9.

13 McLean RM, Williams S, Mann Jl, et al. Blood pressure and hypertension in New Zealand: results from the 2008/09 adult nutrition survey. N Z Med J 2013;126:66-79.

14 Gudala K, Kanukula R, Bansal D. Reduced risk of Parkinson's disease in users of calcium channel blockers: a meta-analysis. Int J Chronic Dis 2015;2015:697404.

15 Hoffman M. Isradipine fails to slow early Parkinson disease progression in phase 3 study, 2019. Available: https://www. neurologylive.com/conferences/aan-2019/isradipine-fails-slow-earlyparkinson-disease-progression-phase-3-study [Accessed 04 Nov 2019].

16 Yue X, Li H, Yan H, et al. Risk of Parkinson disease in diabetes mellitus: an updated meta-analysis of population-based cohort studies. Medicine 2016;95:e3549.

17 Lu L, Fu D-L, Li H-Q, et al. Diabetes and risk of Parkinson's disease: an updated meta-analysis of case-control studies. PLoS One 2014:9:e85781.

18 Brakedal B, Flønes I, Reiter SF, et al. Glitazone use associated with reduced risk of Parkinson's disease. Mov Disord 2017;32:1594-9.
19 Svenningsson P, Wirdefeldt K, Yin L, et al. Reduced incidence of Parkinson's disease after dipeptidyl peptidase-4 inhibitors-A nationwide case-control study. Mov Disord 2016;31:1422-3.

20 Patil SP, Jain PD, Ghumatkar PJ, et al. Neuroprotective effect of metformin in MPTP-induced Parkinson's disease in mice. Neuroscience 2014;277:747-54.

21 Bayliss JA, Lemus MB, Santos VV, et al. Metformin prevents nigrostriatal dopamine degeneration independent of AMPK activation in dopamine neurons. PLoS One 2016;11:e0159381.

22 Kuan Y-C, Huang K-W, Lin C-L, et al. Effects of metformin exposure on neurodegenerative diseases in elderly patients with type 2 diabetes mellitus. Prog Neuropsychopharmacol Biol Psychiatry 2017;79:77-83.

23 Miller DH, Hornabrook RW, Dagger J, et al. Ethnic and HLA patterns related to multiple sclerosis in Wellington, New Zealand. J Neurol Neurosurg Psychiatry 1986;49:43-6.

24 Pearson JF, Alla S, Clarke G, et al. Multiple sclerosis in New Zealand Māori. Mult Scler 2014;20:1892-5.

25 Van Den Eeden SK, Tanner CM, Bernstein AL, et al. Incidence of Parkinson's disease: variation by age, gender, and race/ethnicity. Am J Epidemiol 2003;157:1015-22.

26 Abbas MM, Xu Z, Tan LCS. Epidemiology of Parkinson's diseaseEast versus West. Mov Disord Clin Pract 2018;5:14-28.

27 Willis AW, Evanoff BA, Lian M, et al. Metal emissions and urban incident Parkinson disease: a community health study of Medicare beneficiaries by using geographic information systems. Am J Epidemiol 2010;172:1357-63.

28 Deloitte. Living with Parkinson's disease: challenges and positive steps for the future. Available: https://www2.deloitte.com/au/en/ pages/economics/articles/living-with-parkinsons-disease.html [Accessed 11 Jan 2019].

29 Loesch DZ, Tassone F, Lo J, et al. New evidence for, and challenges in, linking small CGG repeat expansion FMR1 alleles with Parkinson's disease. Clin Genet 2013;84:382-5.

30 Queensland Health. The burden of disease and injury in Queensland's Aboriginal and Torres Strait Islander people 2017 (reference year 2011). Available: https://www.health.qld.gov.au/ data/assets/pdf_file/0024/660840/BoD-MainReport-FINAL.pdf [Accessed 17 Jan 2019].

31 GBD 2015 Neurological Disorders Collaborator Group. Global, regional, and national burden of neurological disorders during 1990-2015: a systematic analysis for the Global Burden of Disease Study 2015. Lancet Neurol 2017;16:877-97.

32 Alamri Y, MacAskill M, Anderson T, et al. Parkinson's disease in the Gulf countries: an updated review. Eur Neurol 2015;74:222-5.

33 Yacoubian TA, Howard G, Kissela B, et al. Racial differences in Parkinson's disease medication use in the reasons for geographic and racial differences in stroke cohort: a cross-sectional study. Neuroepidemiology 2009;33:329-34.

34 Parkinson's Foundation. D Across Race \& Ethnicity: Outreach to the African American Community. Available: https://www.parkinson. org/Living-with-Parkinsons/Resources-and-Support/Podcast/039Parkinsons-Across-Race-Ethnicity-African-American-Community [Accessed 12 Dec 2018].

35 Parkinson Study Group. Pramipexole in levodopa-treated Parkinson disease patients of African, Asian, and Hispanic heritage. Clin Neuropharmacol 2007;30:72-85.

36 Exner DV, Dries DL, Domanski MJ, et al. Lesser response to angiotensin-converting-enzyme inhibitor therapy in black as compared with white patients with left ventricular dysfunction. $N$ Engl J Med 2001;344:1351-7

37 Masoudi FA, Havranek EP. Race and responsiveness to drugs for heart failure. N Engl J Med 2001;345:767. author reply 767-8.

38 Wilson JF, Weale ME, Smith AC, et al. Population genetic structure of variable drug response. Nat Genet 2001;29:265-9.

39 Editorial: census, race and science. Nat Genet 2000;24:97-8 